\title{
Inflammatory Myofibroblastic Tumor of Testis Mimicking Testicular Malignancy
}

\author{
(D) Emre Çamur1 ${ }^{1}$ (D) Deniz Yılmaz², (D) Arzu Develi Çamur3 \\ ${ }^{1}$ Amasya University Faculty of Medicine, Department of Urology, Amasya, Turkiye \\ 2Amasya University Faculty of Medicine, Department of Pathology, Amasya, Turkiye \\ ${ }^{3}$ Suluova State Hospital, Clinic of Internal Medicine, Amasya, Turkiye
}

\begin{abstract}
Here, we report a case of a 62-year-old patient with diabetes and recurrent urethral stricture. He presented with left epididymo-orchitis and ultrasonography showed that there was subsequent mass present in the testicle. He was treated with orchiectomy due to inadequate antibiotic treatment response. Both histology and immunohistochemistry indicated inflammatory myofibroblastic tumor (IMT).

IMT is a known histopathological diagnosis; however, it is rarely found in the testicle. Mostly, a painless mass present in the testicle is the only symptom. Since it cannot be clinically or radiologically distinguished from seminoma, it is usually diagnosed by histopathological examination of the orchiectomy specimen.
\end{abstract}

Keywords: Inflammatory tumor, testicle, malignancy

\section{Introduction}

An inflammatory myofibroblastic tumor (IMT) is a known histopathological diagnosis but extremely rare, and are most commonly found in the lungs, abdomen, and retroperitoneum; reported cases of IMT in the testicle are limited $(1,2)$.

The exact disease etiology remains unknown. Case reports presenting HIV-positive cases suggest that immunodeficiency may play a role in the etiology. Additionally, a clonal rearrangement of anaplastic lymphoma kinase ( $A L K)$ gene (2p23, anaplastic lymphoma kinase) is observed approximately in $50 \%$ of the cases $(1,2,3)$.

Mostly, a painless mass present in the testicle is the only symptom. Since IMT cannot be distinguished clinically or radiologically from seminoma, it is not possible to make a definitive diagnosis clinically and radiologically due to which it is detected by histopathological examination of orchiectomy specimen (2). IMT treatment is based on surgical excision.

\section{Case Report}

A 62-year-old patient with diabetes who performs intermittent urethral self-dilatation for recurrent urethral stricture presented with left scrotal pain and swelling, which had persisted for 1 week.

Physical examination revealed fever at $38{ }^{\circ} \mathrm{C}$ and that the left testicle was sensitive and was three times larger than the right. Laboratory tests suggested leukocytosis, and ultrasonographic examination showed left spermatic cord edema, heterogeneity, parenchymal edema, and increased blood supply in the left testicle, with no mass lesion.

Intravenous ceftriaxone $2 \times 1$ gr antibiotherapy with nonsteroidal anti-inflammatory infusions was started. Three days after initial therapy, no regression was noted in clinical findings, thus after investigations for infectious diseases were conducted, the patient was hospitalized and antibiotherapy was switched to $3 \times 1 \mathrm{gr}$ meropenem.

The patient's complaints subsided with meronem therapy, edema in the testicle decreased, and testicular sensitivity disappeared.

Correspondence: Emre Çamur MD, Amasya University Faculty of Medicine, Department of Urology, Amasya, Turkiye E-mail: emre.camur@outlook.com ORCID-ID: orcid.org/0000-0002-9915-9235

Received: 19.12.2020 Accepted: 05.02.2021

Cite this article as: Çamur E, Yılmaz D, Develi Çamur A. Inflammatory Myofibroblastic Tumor of Testis Mimicking Testicular Malignancy. J Urol Surg 2021;8(3):223-225

๑Copyright 2021 by the Association of Urological Surgery / Journal of Urological Surgery published by Galenos Publishing House. 
After infection parameters returned to normal levels, he was discharged from the hospital with oral antibiotherapy. During a 1-week ambulatory follow-up, the patient had no fever nor testicular pain; however, the left testicle was still two times larger than the right. Nevertheless, a mass or abscess was not noted. However, control ultrasonographic examination showed a 2-centimeter hypoechoic mass in the middle part of the testis without blood flow. Thus, surgery was performed on the patient with tumor markers within normal limits. Due to the partial response to antibiotherapy and the highly infectious appearance of the testicle and its attachments observed in intraoperative evaluation, left orchiectomy was performed, although there was no palpable mass in the testicle. Histopathological examination was performed in the pathology department.

Microscopic examination revealed a lesion area consisting of proliferated spindle cells with myofibroblastic differentiation, which was adjacent to seminiferous tubules and showed signs of intensive inflammation. In the stroma, a mixed-type chronic inflammation with the predominance of lymphocytes and plasma cells accompanied by a few eosinophils was observed. Neither mitotic activity nor pleomorphism and necrosis were observed. Immunohistochemical examination showed that smooth muscle actin was positive, vimentin was strongly positive, and desmin was positive in the proliferative spindle myofibroblastic cells (Figures 1, 2). The Ki-67 proliferation index was 2-3\%. Based on the histopathological findings, IMT was diagnosed.

The patient was followed up after pathological evaluation, and no signs of recurrence or additional organ involvement were observed in contrast-enhanced CT 3 months after the surgery.

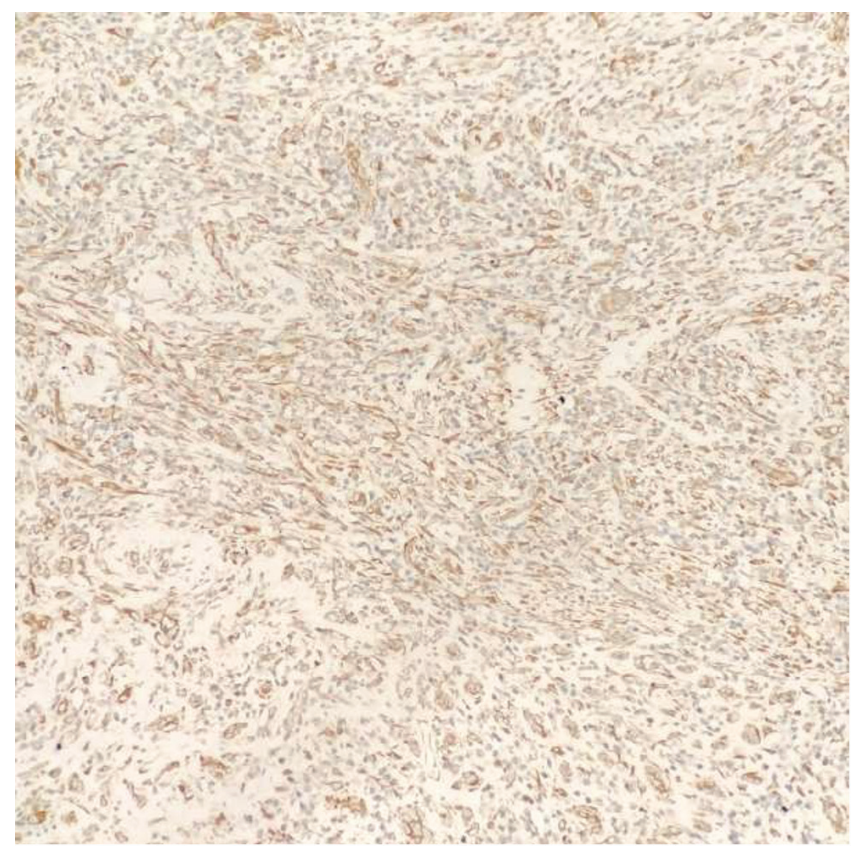

Figure 1. Vimentin positivity of proliferated spindle myofibroblastic cells (immunostain, magnification $\times 200$ )

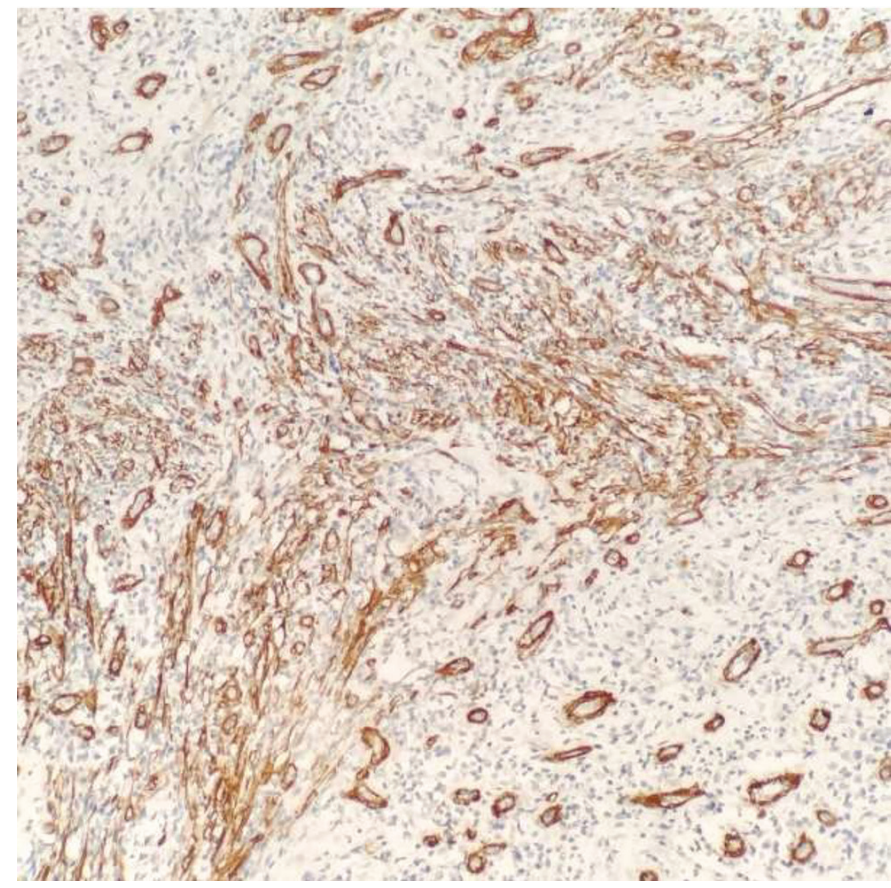

Figure 2. Smooth muscle actin positivity of proliferated spindle myofibroblastic cells and vascular structures (immunostain, magnification $\mathrm{x} 200$ )

\section{Discussion}

IMT is a benign tumor known in the literature with different names such as inflammatory pseudotumor, pseudosarcomatous myofibroblastic proliferation, pseudosarcoma, atypical myofibroblastic tumor, and proliferative funiculitis. Although it can be seen in all age groups, it is most common in children and adolescents. It mostly affects the lungs; however, it is most commonly found in bladder in urinary system $(1,4)$.

Testicular IMT is extremely rare and only a few cases have been reported in the literature. Its etiology remains unknown. A review of literature shows that trauma, infection, genetic predisposition, and immunodeficiency may play a role (5). The $A L K$ gene is seen to be a significant factor because of its clonal rearrangement in $50 \%$ of cases $(1,2,5)$.

Generally, it presents as a painless mass in the testicle, and it is not often distinguished from malignant tumors clinically and radiologically. Therefore, diagnosis is usually made by histopathology of the orchiectomy specimen $(2,3,5)$.

Surgical intervention is the treatment of choice. Recurrence after surgery is possible, especially if the surgical margins are not free from tumors (4). Often its clinical course is benign, thus the risk of metastasis is considerably low; therefore, no aggressive therapy after removal of the tumor is required $(1,6)$.

In a pathological examination, a typical IMT displays spindle cell proliferation in edematous myxoid stroma associated 
with granulation tissue and a mixture of acute and chronic inflammatory cells (5).

Immunohistochemistry enables exact diagnosis and helps distinguish IMT from similar tumors such as inflammatory fibrosarcoma and malignant fibrous histiocytoma.

Usually, immunoreactivity is seen for muscle-specific actin, smooth muscle actin, vimentin desmin, and ALK, but not for S100 protein myoglobin $(3,5,7,8)$.

\section{Conclusion}

The etiology of IMT is unclear. The presence of diabetes in our patient indicates that immunodeficiency may play a role in the etiology of this disease. Therefore, it should be considered in testicular masses occurring after or during testicular infection in patients with immunodeficiency. By performing partial orchiectomy including the whole mass in such patients, unnecessary orchiectomy and organ loss can be prevented when the frozen section shows no signs of malignancy.

\section{Ethics}

Informed Consent: Patient's approval was taken.

Peer-review: Externally peer-reviewed.

\section{Authorship Contributions}

Surgical and Medical Practices: E.Ç., D.Y., Concept: E.Ç., Design: E.Ç., A.D.Ç., Data Collection or Processing: E.Ç., Analysis or Interpretation: E.Ç., Literature Search: E.Ç., A.D.Ç., Writing: E.Ç., A.D.Ç.
Conflict of Interest: No conflict of interest was declared by the authors.

Financial Disclosure: The authors declared that this study received no financial support.

\section{References}

1. Voelker HU, Kuehn D, Strehl A, Kircher S. Testicular Inflammatory Myofibroblastic Tumor: A Known Entity at a Very Rare Site. Case Rep Urol 2017:1-4.

2. Oberoi M, Reddy T, Gordetsky JB, Thomas JV, Rais-Bahrami S. Benign testicular neoplasm in a human immunodeficiency virus-positive patient masquerading as testicular cancer. Urol Ann 2017;4:393-396.

3. Coffin CM, Hornick JL, Fletcher CD. Inflammatory myofibroblastic tumor: comparison of clinicopathologic, histologic, and immunohistochemical features including ALK expression in atypical and aggressive cases. Am J Surg Pathol 2007;4:509-520.

4. Payal Kapur, Kristin Treat, Alex Tzu-Yueh Chuang, and Mai P. Hoang Pathologic Quiz Case: Paratesticular Mass in a Young Man. Archives of Pathology \& Laboratory Medicine 2004;5:589-590.

5. Dangle PP, Wang WP, Pohar KS. Inflammatory myofibroblastictumor of epididymis: a case report and review of literature. World J Surg Oncol 2008;6:119.

6. Coffin $\mathrm{CM}$, Watterson J, Priest JR, Dehner LP. Extrapulmonary inflammatory myofibroblastic tumor (inflammatory pseudotumor): a clinicopathologic and immunohistochemical study of 84 cases. Am J Surg Pathol 1995;19:859872.

7. Chakrabarti N, Shetty R. Inflammatory myofibroblastic sarcoma of the spermatic cord. Indian J Surg 2010;2:152-154.

8. Hollowood K, Fletcher CD. Pseudosarcomatous myofibroblastic proliferations of the spermatic cord ("proliferative funiculitis"). Histologic and immunohistochemical analysis of a distinctive entity. Am J Surg Pathol 1992;16:448-454. 